This item was submitted to Loughborough's Research Repository by the author.

Items in Figshare are protected by copyright, with all rights reserved, unless otherwise indicated.

\title{
Modelling transdermal drug delivery using microneedles: effect of geometry on drug transport behaviour
}

PLEASE CITE THE PUBLISHED VERSION

http://dx.doi.org/10.1002/jps.22736

\section{PUBLISHER}

(c) Wiley Periodicals, Inc. and the American Pharmacists Association

\section{VERSION}

AM (Accepted Manuscript)

\section{PUBLISHER STATEMENT}

This work is made available according to the conditions of the Creative Commons Attribution-NonCommercialNoDerivatives 4.0 International (CC BY-NC-ND 4.0) licence. Full details of this licence are available at: https://creativecommons.org/licenses/by-nc-nd/4.0/

\section{LICENCE}

CC BY-NC-ND 4.0

\section{REPOSITORY RECORD}

Olatunji, Ololade, Diganta Bhusan Das, and Vahid Nassehi. 2014. "Modelling Transdermal Drug Delivery Using Microneedles: Effect of Geometry on Drug Transport Behaviour". figshare.

https://hdl.handle.net/2134/16540. 


\section{Modelling Transdermal Drug Delivery Using Microneedles: Effect of Geometry on Drug Transport Behaviour}

Ololade Olatunji, Diganta B. Das*, Vahid Nassehi

Department of Chemical Engineering, Loughborough University, Loughborough LE11 3TU, $U K$

Running title: Effect of microneedle geometry on drug transport

*Corresponding author (D.B.Das@lboro.ac.uk) 


\section{Abstract}

Transdermal drug delivery using microneedles depends on the rate of drug transport through the viable epidermis. Therefore minimizing the distance between the drug loaded surface and the microcirculation in the dermis where the drug is absorbed into the body is significant in improving drug delivery efficiency. A quantifiable relationship between microneedle design parameters and skin diffusion properties is therefore desirable, which is what this study aims to achieve. A framework is presented to quantitatively determine the effects of design parameters on drug diffusion through skin, where the effects of compressive strain on skin due to insertion of microneedle are considered. The model is then used to analyse scenarios of practical importance. For all scenarios analysed, predicted steady state flux was found to be lower when effect of microneedle strain on diffusion coefficient was accounted for. For example simulations results indicated increasing tip radius from $5 \mu \mathrm{m}$ to $20 \mu \mathrm{m}$ flux increased from $6.56 \times 10^{-6} \mathrm{~mol} / \mathrm{m}^{2} / \mathrm{s}$ to $7.02 \times 10^{-6} \mathrm{~mol} / \mathrm{m}^{2} / \mathrm{s}$ for constant diffusion coefficient. However if the effect of strain on diffusion coefficient is considered, the calculated flux increases from $5.30 \times 10^{-6} \mathrm{~mol} / \mathrm{m}^{2} / \mathrm{s}$ to a peak value of $5.32 \times 10^{-6} \mathrm{~mol} / \mathrm{m}^{2} / \mathrm{s}$ (at $10 \mu \mathrm{m}$ ) and decreases to $5.29 \times 10^{-6} \mathrm{~mol} / \mathrm{m}^{2} / \mathrm{s}$. This paper contributes by reporting a framework to relate microneedle geometry to permeability with inclusion of the possible effects the microneedle design may pose on the diffusion coefficient.

Keywords:

Skin, simulations, permeability, pharamcokinetics, mathematical model, diffusion, transdermal drug delivery, drug transport 


\section{Introduction}

Microneedles technology is seen as one of the most promising options for painless and minimally invasive drug delivery compared with other options such as electroporation [1], ultrasound [2] and use of chemical penetration enhancers such as sodium lauryl sulphate [3]. Microneedles have been designed to pierce through the stratum corneum (SC) in order to deliver drugs to the viable epidermis (VE) where the drug molecules diffuse more easily into the dermis from where they are absorbed into the blood vessels. Studies have shown that microneedles increase the skin permeability of molecules such as Insulin and Calcein through the skin [4-5] albeit giving little attention to the possibilities of different microneedle designs having varying effects on drug delivery efficiency. There have been previous studies that considered the effect of microneedle geometry on the permeability [6-9]. For example, Davidson et al [9] identified the effect of using different microneedle geometry on the permeability of drug in skin. In this study the diffusion coefficient of the drug in the skin was assumed to be the same when the microneedles were inserted and removed. However, other studies have shown that permeability through soft tissue can be significantly altered when a mechanical strain is exerted. In transdermal drug transport the efficiency of drug delivery is dependent on the rate at which the drugs diffuse through the skin. Therefore, the change in the intrinsic diffusion property of the skin when microneedles are inserted must be given careful considerations, particular when the microneedles are inserted for long duration.

The effect of tissue compression on solute or drug permeability has been shown to be important in some studies. These include experiments on articular cartilage [10-13] and nucleus pulposus and fibrosus [14-15] to analyse the effect of placing compressive force of specimen on the permeation of solutes. In these studies, it was shown that compressive straining of tissue will cause the permeability of molecules through it to decrease. Roxhed et 
al [16] had previously carried out simulations that showed that when microneedles are inserted high hydrostatic pressures are generated in regions of the skin. To counter this they designed ultra-sharp hollow microneedles with side openings. Histological samples showed that these hollow microneedles were able to pierce human skin. However, observations from staining showed that there was leakage when fluid was injected into the skin through the hollow microneedles. The study attempted to locate the holes of hollow microneedles in regions where the pressure exerted by the microneedles is thought to be minimal. However, Roxhed et al [16] did not quantify the effect of the pressure exerted by the microneedle on the permeation of drug through the skin. Furthermore, although designing hollow microneedles with the opening on the side might allow for design of ultra sharp microneedles for easier insertion, other problems associated with hollow microneedles still remains. Design of solid coated and polymer microneedles still persist over hollow microneedles because of their structural and storage advantages [17] and the main mode of delivery of such microneedles is by diffusion through skin. Therefore it is important to consider the changes in diffusion coefficient when such microneedles are left to remain inserted in the skin over the period of the medication.

Considering the above issues, the present study aims to develop a quantitative basis for analysing the relationship between the microneedle geometry and the diffusion coefficient of the skin. It is envisaged that the developed model will allow the design of the microneedle to be optimized for more efficient drug delivery. The contribution of this work is mainly theoretical, although most of the concepts which constitute the model and the simulations are validated with experimental data. The significance of the study is to provide a framework which quantifies the effect of microneedle geometry on drug permeation through skin and subsequently concentration in the blood with the inclusion of the possible effect the microneedle design may pose on the diffusion coefficient. The model and case studies 
simulated illustrate steps and necessary data which would be required to predict performance of microneedle based drug delivery systems. Fentanyl is used as the model drug in the case studies as it is a drug which is widely delivered through the transdermal route [18-20].

\section{Outline of the Conceptual Model}

\section{Structure and permeability of pierced and intact skin}

For the purpose of our work we define the skin to be made up of two distinct layers: the epidermis and the dermis. The epidermis is further divided into two main layers which are the SC and the VE in consistent with other studies [21-22]. Different forms of transport mechanisms have been suggested to describe transdermal transport such as the brick and mortar model [23-28] and the Fick's diffusion models [29-34, 21]. In this study, we shall consider the transport of drug as diffusion through the porous pathway in the VE [35-37]. When microneedles are inserted into the skin, regions of the skin are compressed in a manner which could alter the diffusion coefficient of the skin relative to its unstrained position [16]. This is in accordance with other permeation studies on cartilage tissues that compared diffusivity of strained and unstrained tissues. Indeed, for the case of hollow microneedles a solution to this problem was proposed by Martanto et al [38]. This involved partial retraction of the microneedles to allow delivery of more drugs/fluids to the skin [38, 31]. However the limitations of hollow microneedles such as leakage still persist making solid microneedles a predominant option. However for solid microneedles, which may need to be applied for a long duration, the implications of the microneedle geometry on the drug diffusion should be considered carefully. For example, hydrogel microneedles [39-40] are strong enough to pierce through the skin when dry and upon insertion they absorb moisture from the skin and swell allowing drugs to permeate through them into the skin. This design has an advantage over hollow microneedles as they are less brittle and blockage is eliminated because the drug 
diffuses through the needle, rather than pass through the tiny lumen as it does in hollow microneedles. These types of microneedle drug delivery system requires the microneedles to remain inserted in the skin for longer periods as they are designed to be used, either in combination with a transdermal patch or with the drug encapsulated within the structure of the microneedles from which the release rate can be controlled by the composition of the hydrogel material [39].

\section{Force exerted on the skin by inserted microneedles}

First, the manner in which the skin contracts following insertion of microneedle is analysed in the context of this work and a model is then proposed. When microneedles are inserted into the skin, each exerts a pressure on the skin as it occupies a volume equivalent to the volume of the microneedle. For example, a schematic of the stress distribution in deformed skin when two microneedles are inserted is shown in Figure 1. The non grey regions indicate the non deformed skin while the grey region show the deformed skin with where the microneedles exert compressive force on the skin.

In this study we consider the skin as a homogeneous layer since the only layer being considered is the VE. Although the stress distribution may vary across the skin at distances away from the needle the exerted pressure shall be assumed to be distributed evenly over the area of the skin under the microneedle array. This is thought to be a valid assumption to make here since the skin is a non rigid surface and the microneedles are micron sized objects. Therefore, for a tightly packed microneedle array the stress will be evenly distributed around the diffusion region. This exerted force on the skin causes a decrease in the pore size in the VE. The total decrease in pore size is therefore equal to the total volume of microneedles. 


\section{Strain-dependent change in diffusion coefficient}

For the purpose of this study, the dimensions defined are those of the part of the microneedles that is inserted into the viable epidermis. The full design length will not insert due to the elastic nature of the skin, presence of tiny wrinkles and hairs as observed in several studies [4, 57-59]. The dimensions are chosen based on the geometries that have been fabricated in literature and this is consistent with previous studies which looked at modelling MNs for drug delivery [6-9]. Drug diffusing through the VE is modelled as diffusion through the porous pathway within the tissue [35-36]. The hypothesized pores are assumed to be of equal sizes and arranged in parallel in the same direction as the general direction of concentration gradient between the solid microneedle surface and the sink that is assumed to exist at the epidermal/dermal junction [40-41]. The diffusion coefficient discussed here is assumed to be isotropic and since the stress is distributed evenly over the region where diffusion takes place, diffusion coefficient is also defined to be isotropic when microneedles are inserted. In other words, the diffusion coefficient is strain-dependent; however, it does not vary with directions and positions. The permeability of drug through the skin is therefore given as [35-37, 42]

$$
\mathrm{K}=\frac{\varepsilon \mathrm{D}_{\mathrm{r}}}{\tau \mathrm{h}}
$$

Where $D_{r}$ is the diffusion coefficient of the drug through the water filled pores within the VE; $\varepsilon$ is the skin porosity, $\tau$ is the tortuosity and $h$ is the thickness of the VE. $D_{r}$ relates both the drug and skin properties and is given as

$$
\mathrm{D}_{\mathrm{r}}=\mathrm{DH}(\lambda)
$$

Where $D$ is the diffusion coefficient of the drug at infinite dilution, $H(\lambda)$ is a hindrance factor. For $\lambda<0.4[43,37]$ the hindrance factor is given by [42, 35]: 


$$
H(\lambda)=(1-\lambda)^{2}\left(1-2.104 \lambda+2.09 \lambda^{3}-0.095 \lambda^{5}\right)
$$

$\lambda$ is the ratio of the hydrodynamic radius of the drug $\left(r_{p}\right)$ and the radius of the hypothesized pores $\left(\mathrm{r}_{\mathrm{s}}\right)$ in the VE

$$
\lambda=\frac{\mathrm{r}_{\mathrm{p}}}{\mathrm{r}_{\mathrm{s}}}
$$

When microneedles are inserted into the skin, the total volume of the skin under the patch is decreased by $n V_{\text {needle, }}$ which is the total volume of $n$ microneedles inserted. The size of the pores will therefore be decreased, however it is assumed here that the length of the pores will not vary, rather the decreased volume will be as a result of the decrease in the size of the hypothesized pores from $r_{s}$ to $r_{s i}$.

$$
\mathrm{V}_{\text {pore }}-\mathrm{V}_{\text {porei }}=\pi \mathrm{r}_{\mathrm{s}}^{2} \mathrm{n}_{\mathrm{p}} \mathrm{x}-\pi \mathrm{r}_{\mathrm{si}}^{2} \mathrm{n}_{\mathrm{p}} \mathrm{x}_{\mathrm{i}}=\mathrm{nV}_{\text {needle }}
$$

Where $\mathrm{V}_{\text {pore }}$ and $\mathrm{V}_{\text {porei }}$ represents the volume of the pores before and after microneedles have been inserted; $r_{s}$ and $r_{s i}$ represent the radius of the pore before and after microneedles have been inserted into the skin. Path length of diffusion, $x$, is defined as:

$$
\mathrm{x}=\tau \mathrm{h}
$$

The subscript $\mathrm{i}$ indicates microneedle inserted and $\mathrm{h}$ represents the effective skin thickness, $\mathrm{n}_{\mathrm{p}}$ is the number of pores in the skin area, and this is obtained from the total area of the pores in the skin divided by the area of a single pore.

$$
n_{p}=\frac{s A}{\pi \pi r_{s}^{2}}
$$


A is the area under the microneedle array, $\varepsilon$ is porosity, and $\tau$ is tortuosity. We can therefore relate this decrease in pore size due to microneedle inserted with the diffusion coefficient. Where the radius of pores with microneedles inserted given as:

$r_{s i}=\sqrt{\frac{V_{\text {pore }}-n V_{\text {negdle }}}{\pi n_{p} x}}$

Where $\mathrm{V}_{\text {pore }}$ is the volume of pores in the skin prior to microneedle insertion; $\mathrm{V}_{\text {needle }}$ is the volume of each microneedle, $\mathrm{n}$ is the number of microneedles in the array. This solution for $\mathrm{r}_{\mathrm{si}}$ can then be substituted into equation 2 to find $\lambda$ giving the diffusion coefficient with microneedle inserted as

$$
D_{r}=D H\left(\frac{r_{p}}{\sqrt{\frac{V_{\text {pore }}-n V_{\text {needle }}}{\pi n_{p} x}}}\right)
$$

Using this model the geometry of microneedle can thus be related to drug permeability in the skin (equations 1 and 9). It can be noted that where microneedles are not used $\mathrm{n}$ becomes zero $(n=0)$ and equation (9) gives the diffusion coefficient for skin without microneedle inserted based on the porous pathway theory. The values for the necessary parameters used in this study are listed in Table 1. Skin thickness varies in different parts of the skin [44] the value used here is the skin thickness in the arm which is a practical region for placing a microneedle array.

\section{Drug transport behaviour}

The presented model will be analysed using 3D simulations to obtain the effective skin thickness and steady state diffusive flux followed by simulations to predict blood concentration profile. Two separate cases will be considered; with the effect of microneedle strain on skin accounted for and where the effect of the microneedle strain is ignored. 


\section{Drug permeation in skin}

The 3-D simulations for drug transport in skin are carried out using $\mathrm{COMSOL}^{\circledR}$ (COMSOL 3.0, Multiphysics Software from Comsol, 2005) is simulation software with an easy to use practical interface that is able to solve problems in all dimensions using the finite element method. Using COMSOL the model structure can be drawn using the built in model builder and the properties of each region defined with necessary boundary conditions imposed as required. In this particular study, a microneedle inserted into a given area of skin is modelled as a tapered structure inserted in a block. The boundary conditions are then defined such that the base of the block serves as a sink and the sides of the block are insulated against diffusion (i.e. zero flux). The concentration is defined on the surface of the microneedle as constant throughout the process and the sub domain settings are used to define the diffusion properties of Fentanyl in the skin and microneedles. The problem is then solved to obtain flux values at the base of the skin for the different geometries considered.

Diffusion through the SC is eliminated by the use of microneedles; therefore the diffusion coefficient that is relevant in this case is that of the VE. We model the steady state diffusion of drugs from the surface of the microneedles into the skin [45-46] from Fick's diffusion model $[34,16]$ :

Parameters obtained from the developed model (i.e. $\varepsilon \mathrm{D}_{\mathrm{r}}$ and $\mathrm{x}$ ) are implemented in $\mathrm{COMSOL}^{\circledR}$ in order to fit the porous pathway model into the Fick's law. The concentration at the base is defined as 0 assuming $100 \%$ absorption in the dermis (i.e. all drug reaching the dermis is immediately absorbed into the blood vessels). Therefore a sink condition exists in this region. Similar assumptions have been used in other studies on transdermal drug delivery $[47,34,16]$. The following boundary conditions are implemented in all simulations: 
The initial drug concentration at time $t=0$ in skin is 0

$$
\mathrm{C}=0 \quad \text { at } \quad 0 \leq \mathrm{x} \leq \mathrm{L} \text { for } \mathrm{t}=0
$$

The concentration of drug on the skin surface $C_{s}$, remains constant throughout the duration of application since the concentration of Fentanyl in the formulation is very high.

$$
\mathrm{C}=\mathrm{C}_{\mathrm{s}} \text { at } \quad 0 \leq \mathrm{x} \leq \mathrm{L} \text { for } \mathrm{t}>0
$$

Assuming $100 \%$ absorption, that is, as drug diffuses through the epidermis it is immediately absorbed into the microcirculation in the dermis; therefore, at the epidermal/dermal junction (at the base of the block/skin model) the concentration remains constant as 0 .

$\mathrm{C}=0 \quad$ at $\quad \mathrm{x}=\mathrm{h}$ for $\mathrm{t}>0$

At steady state the time variation is eliminated such that $\mathrm{dC} / \mathrm{dt}=0$. The steady state diffusive flux is calculated by rearranging the Fick's first law for steady state diffusion $[47,34,16]$.

$$
\mathrm{J}_{\mathrm{ss}}=-\mathrm{D} \frac{\mathrm{dC}}{\mathrm{dx}}
$$

Where $\mathrm{J}_{\mathrm{ss}}$ is the steady state flux of Fentanyl across skin, $\mathrm{D}$ is the diffusion coefficient, $\mathrm{C}$ is the concentration of Fentanyl and $\mathrm{dC} / \mathrm{dx}$ is the concentration gradient. The following applies at steady state;

$$
\frac{\mathrm{dC}}{\mathrm{dx}}=\text { constant }=\frac{\mathrm{C}_{0}-\mathrm{C}_{\mathrm{s}}}{\mathrm{h}_{\mathrm{eff}}}
$$

Where $\mathrm{C}_{\mathrm{s}}$ is drug concentration on the surface of microneedles, $\mathrm{C}_{0}$ is the concentration at the epidermal/dermal junction.

By combining equation (13) with equation (14), and given that $C_{0}=0$, we obtain the following equation for steady state diffusive flux $\mathrm{J}_{\mathrm{ss}}$ :

$\mathrm{J}_{\mathrm{ss}}=\frac{\mathrm{DC}_{\mathrm{s}}}{\mathrm{h}_{\mathrm{eff}}}$

Effective skin thickness is then calculated by rearranging equation (20) for $\mathrm{h}_{\mathrm{eff}}$. 


\section{Drug concentration in blood}

When the drug on the microneedle diffuses into the skin, it is absorbed into the microcirculation after which it is eliminated from the body. The blood concentration profile of a drug after microneedle delivery is predicted using SKIN-CAD. The software combines both the physicochemical parameters for diffusion of the drug through the skin and pharmacokinetics of the drug in the blood to simulate the drug distribution profile in the body using the finite difference method. Various models have been proposed to model the pharmacokinetics of different drugs absorption and elimination in the body and these have been reviewed by Hacker et al [48], here a one compartment model is adopted as it has been shown to be applicable to transdermal drug delivery since this mode of delivery bypasses absorption in the stomach and intestine. The one compartment model which was developed by (equation 16) has also been validated against experimental results to be a good approximation for predicting drug concentration in blood following transdermal delivery of Fentanyl [49]. In another study, concentration profiles following transdermal delivery of Fentanyl using a conventional patch was obtained from various patients and was shown the match simulations carried out in SKIN-CAD [19].

$V_{d} \frac{d C_{b}}{d t}=\frac{d Q}{d t} A_{n}-k_{e} C_{b} V_{d}$

$V_{d}$ is the volume of distribution in the blood, $C_{b}$ is the concentration of the drug in the blood at time $t, k_{e}$ is the elimination rate constant, $d Q / d t$ is the rate of skin penetration, $A_{n}$ is the area of the drug releasing surface of the delivery system, which is calculated as the surface area of the microneedles in contact with the VE. 


\section{Results and Discussions}

\section{Comparing modelling with experimental results}

Here we compare diffusion coefficient values determined from the proposed framework with experiment carried out on bovine annulus fibrosus (AF) given that there seems to be no experiments on diffusion under compression for the VE. In the absence of such experimental studies on skin, experiment on bovine AF will suffice for the purpose of validating the developed framework in this paper since for both tissues, drug transport can be modelled as diffusion through porous pathway and compression will result in decreased pore size. Jackson et al [16] studied the effect of strain level on the diffusion coefficient of glucose through bovine AF. Results for $0 \%, 10 \%$ and $20 \%$ strain showed a decrease in diffusion coefficient as strain level increased. The strain is the ratio of change in volume due to compression to the initial volume of tissue before deformation. In this case it is expressed as the volume of $\mathrm{MN}$ inserted to the volume of skin under the array expressed in percentage. To compare these results with the model proposed in this study, microneedle geometries were determined to exert similar strains on the skin. The strain is calculated from equation (17) where $V_{\text {needle }}$ is the volume of the $\mathrm{MN}$ penetrating the $\mathrm{VE}$ and $\mathrm{V}_{\text {skin }}$ is the volume of skin under the $\mathrm{MN}$ array. Using equation (17), it was found that geometry with base radius, tip radius and length of $110 \mu \mathrm{m}, 10 \mu \mathrm{m}$ and $130 \mu \mathrm{m}$, respectively, caused a $10 \%$ strain and likewise $110 \mu \mathrm{m}, 75 \mu \mathrm{m}$ and $130 \mu \mathrm{m}$ caused a $20 \%$ strain for a $1 \times 10^{-7} \mu \mathrm{m}^{2}$ array containing 100 microneedles.

$$
\phi=\frac{\mathrm{nV}_{\text {needle }}}{\mathrm{V}_{\text {skin }}}
$$

Where

$$
\mathrm{V}_{\text {skin }}=\mathrm{Ah}
$$


Hydrodynamic radius and diffusion coefficient (in interstitial fluid) of glucose was taken to be $3.8 \times 10^{-10} \mathrm{~m}$ [49] and $1.63 \times 10^{-10} \mathrm{~m}^{2} / \mathrm{s}$ [50], respectively. The model and experiment both show lower diffusion coefficient at higher strain level as shown in Figure 2 with comparable values of diffusion coefficient. The diffusion coefficient of a particular drug molecule in tissue depends on the tortuosity and porosity and pore size and these varies for different tissues. Assuming the porosity of AF would be higher than that of skin, porosity and tortuosity are estimated to be 0.1 and 2 respectively using the relatively high values reported in literature [37] in order to obtain a close comparison. The differences between the experimental and model values are attributable to the estimated tortuosity and porosity used in the predictions. Nonetheless, the experiment is useful in validating the model which suggests that the diffusion coefficient for such deformable tissue (AF or skin) should drop as strain is increased. Further experiments which demonstrate the concept of strain having an effect on the permeation of substances through tissue such as nucleus fibrosus, muscle and cartilage tissue has been presented in several texts [52-54, 11-13].

Transdermal drug delivery using a microneedle inserted in the skin is modelled in 3-D using the method described in preceding section. Table 1 show the parameters used in this study for varying the needle geometry for a tapered needle.

\section{Effect of geometry of microneedle array design on diffusive flux}

To further determine the significance of the effect of the compressive force exerted by the needle on the diffusivity of the drug in the skin the diffusive flux and peak drug concentration in blood are obtained for different microneedle geometries. The two cases considered are: 1) the diffusion coefficient calculated using equation (10), 2) diffusion coefficient remaining constant despite inserted microneedles. Diffusive flux at the epidermal/dermal junction was obtained for different microneedle geometries by varying the length of microneedle (L), the 
tip radius (r) and base radius (R). In order to carry out the simulations for a plane drug with no pores, the diffusion path length based on the porous pathway model was converted to the diffusion path length for a non porous drug by multiplying the turtuorsity by the thickness of the skin (equation 6). For all simulations, except were the listed parameter is being varied, the dimensions used are $\mathrm{L}=150 \mu \mathrm{m}, \mathrm{R}=80 \mu \mathrm{m}, \mathrm{r}=5 \mu \mathrm{m}$ and $\mathrm{n}=25$.

It is expected that if the size of microneedles are increased, this will allow more surface for drug loading for solid microneedles. This expected pattern is seen when the diffusion coefficient is assumed to be independent of the inserted microneedles as the simulation results from previous studies indicated $[9,55]$. However, the theory available suggests that this might not be the case when the compressive force exerted by the microneedle is accounted for as discussed in the preceding sections. This is shown in Figures 3-6 where the diffusive flux at the skin/blood interface for both the above cases are compared. These results have taken account of both the diffusion pattern and the force exerted on the skin when the microneedle is inserted by using 3D simulations in combination with the framework presented in this study to determine the diffusion coefficient with microneedles inserted. From the results shown in Figures 3-6, it is evident that the flux is higher for the case where diffusion coefficient is assumed to be constant. In Figures 4 and 5, increasing the tip and base radius decreased the flux when the effect of compression was accounted for using the presented model. However results shown in Figure 3 suggest that increasing the length of the microneedle has less effect on the diffusion coefficient of the drug such that the advantage of decreasing the path length by increasing the penetration depth manifests as an increase in flux. The results in Figure 6 show the effect of increasing number of microneedles on drug flux through skin, is in accordance with the results from experiments done by Yan et al [56]. In the said study it was shown that when the density of microneedles in an array is increased, 
the flux of acyclovir through human cadaver epidermis decreases. It was also shown that increasing the length of the microneedles resulted in increased flux however further results from the same study [56] showed that this is not always the case. The results The simulations carried out here indicates that this pattern observed in the experimental results may be explained by the proposed theory which suggest permeability to be an interplay between decreased skin thickness and increased strain on skin leading to decreased diffusion coefficient. This indicates a threshold beyond which increasing the size of microneedles will result in decreased permeability of the skin due to decreased diffusion coefficient. Figures 3-6 are presented with two vertical axes in order to show the change in flux for the two cases considered, the significance of these differences depends on the level of precision required for individual cases.

\section{Effect of geometry of microneedles on concentration profiles}

To elucidate the significance of the compressive force further, the next step was to predict the blood concentration profiles after the microneedle has been inserted into skin for 4 hours. For this purpose we use a model drug, Fentanyl with properties listed in Table 1. Two cases considered are again, i.e., 1) the diffusion coefficient calculated using equation (10), 2) diffusion coefficient remaining constant despite inserted microneedles. The total surface area of the microneedles was calculated and represented as the surface area of transdermal drug delivery device for the stripped skin scenario. The results indicate a decrease in peak blood concentration when the compressive force of the needle is taken into account, compared to when the diffusion coefficient is assumed to be constant despite needle insertion. Blood concentration, for example, decreases from $0.00261 \mathrm{ng} / \mathrm{ml}$ to $0.00239 \mathrm{ng} / \mathrm{ml}$ when microneedles base radius was decreased from $95 \mu \mathrm{m}$ to $85 \mu \mathrm{m}$ this is shown in Figure 7 . The predicted peak drug concentration in blood also increases as the tip radius and the penetration 
length were increased as shown in Figures 8 and 9. This implies that the effect of the force exerted by the inserted microneedles on the diffusion coefficient is significant enough to indicate a lower value for the predicted concentration of the drug in the blood. Although increasing the size and number of microneedles in an array decreases the average path length of diffusion, it may still cause a drop in the diffusion coefficient to an extent where the advantage of increasing the size and density of microneedles may become obsolete. This is evident in the results displayed in Figure 10. Increasing the number of microneedles increased the peak concentration of the drug in the blood, however increasing the number of microneedles beyond 75 resulted in a decreased peak concentration.

The case studies that have been simulated here illustrate how varying the design of microneedle structures can be used to vary the delivery rate for microneedle mediated drug delivery. This harnesses the advantage of microneedles to deliver drug in precise amount. This study presents a framework to use the design of microneedles for controlled drug delivery while taking into account the change in the diffusion coefficient due to the strain exerted on the skin.

\section{Conclusion}

This study presents a quantitative method for relating the geometry of microneedles to permeability of drug through the skin for the purpose of improving controlled release of drug from microneedle based drug delivery systems. The presented model takes into consideration possible change in diffusion coefficient of the skin due to insertion of microneedle and the significant of accounting for the change in diffusion coefficient due to strain exerted on the skin is illustrated in the presented case studies based on mathematical simulations to show predictions of drug concentration profiles in the skin and blood. Results obtained indicate that increasing the size and density of microneedles in an array would increase the compressive 
force exerted by the microneedles on the skin and this leads to decreased drug permeability. Future works could be directed at obtaining experimental data for specific cases and fitting into the model for optimization of microneedle design prior to fabrication. Such studies are essential in the clinical and commercial development of MNs for drug delivery.

\section{Acknowledgement}

The authors gratefully acknowledge an EPSRC (Engineering and Physical Sciences Research Council, UK) studentship towards this PhD research.

\section{References}

1] Banga AK, Bose S, Ghosh TK, 1999. Iontophoresis and electroporation: comparisons and contrasts. Int. J. Pharm 179:1-19.

2] Byl NN, 1995. The use of ultrasound as an enhancer for transcutaneous drug delivery: phonophoresis. Phys Ther 75:539-553.

3] Ogiso T, Iwaki M, Paku T, 1995. Effect of various enhancers on transdermal penetration of indomethacin and urea, and relationship between penetration parameters and enhancement factors. J Pharm Sci 84:482-488.

4] Henry S, McAllister VD, Mark GA, Prausnitz RM 1998. Microfabricated microneedles: A novel approach to transdermal drug delivery. J Pharm Sci 87: 922-925.

5] McAllister DV, Wang PM, Davis SP, Park JH, Canatella PJ, Allen MG, Prausnitz MR 2003. Microfabricated needles for transdermal delivery of macromolecules and nanoparticles: fabrication methods and transport studies. PNAS 100:13755-13760.

6] Al-Qallaf B, Das DB 2008. Optimization of square microneedle arrays for increasing drug permeability in skin. Chemical Engineering Science 63:2523-2535. 
7] Al-Qallaf B, Das DB 2009a. Optimizing microneedle arrays to increase skin permeability for transdermal drug delivery. Annals of the New York Academy of Sciences 1161: 8394.

8] Al-Qallaf B, Das DB 2009b. Optimizing microneedle arrays for transdermal drug delivery: Extension to non-square distribution of microneedles. Journal of Drug Targeting, 17: 108-122.

9] Davidson A, Al-Qallaf B, Das DB, 2008. Transdermal drug delivery by coated microneedles: Geometry effects on effective skin thickness and drug permeability. Chemical Engineering Research and Design 86:1196-1206.

10] Evans RC, Quinn TM, 2005. Solute Diffusivity correloates with Mechanical Properties of Matrix Density of Compressed Articular Cartilage. Arch Biochem Biophys 442: 1-10.

11] Quinn TM, Kocian P, Meister J, 2000. Static Compression is Associated with Decreased Diffusivity of Dextrans in Cartilage Explants, Archives of Biochemistry and Biophysics. 384: 327-334.

12] Leddy HA, Guilak F, 2008. Site-Specific Effects of Compression on Macromolecular Diffusion In Articular Cartilage. Biophys J 95:4890-4895.

13] Reynaud B, Quinn TM, 2006. Anisotropic Hydraulic Permeability in Compressed Articular Cartilage. J Biomechs 39: 131-137.

14] Jackson RA, Yuan T, Huang CC, Travascio F, Gu WY, 2008 Effect of Compression and Anisotropy on the Diffusion of Glucose in Annulus Fibrosus, National Institute of Health. 33: $1-7$.

15] Heneghan P, Riches PE, 2008. Determination of the strain-dependent hydraulic Permeability of the Compressed Bovine Nucleau Polposus. Journal of Biomechanics 41: 903-906. 
16] Roxhed TN, Gasser C, Griss P 2007. Penetration Enhanced Ultrasharp Microneedles and Prediction in Skin Interaction for Efficient Transdermal Drug Delivery. Journal of Microelectromechanical systems 16: 1429-1440.

17] Gill S H, Prausnitz RM, 2006. Coated microneedles for transdermal drug delivery. Journal of controlled release 117: 227-237.

18] Taghizadeh SM, Soroushnia A, Mohamadnia F 2010. Preparation and in Vitro Evaluation of a New Fentanyl Patch Based on Functional and Non-functional Pressure Sensitive Adhesives. AAPS PharmSicTech 11: 279-284.

19] Tojo K 2005. Mathematical Models of Transdermal and topical drug delivery, $2^{\text {nd }}$ ed. Japan: Biocom systems Inc. ISBN: 4-9901108-2-X (978-4-9901108-2-6).

20] Roy SD, Gutierrez M, Flynn LG, Cleary WG 1996. Controlled Transdermal Delivery of Fentanyl: Characterizations of Pressure-Sensitive Adhesives for Matrix Patch Design. J. Pharm Sci. 85: 491-495.

21] Okamoto H, Yamashita F, Saito K, Hashida M, 1989. Analysis of Drug Penetration Through the Skin by the Two-Layer Skin Model, Pharm Res 6: 931-973.

22] Lv YG, Lie J, Xu B 2006. Modeling of transdermal drug delivery with a microneedle array. J Micromech Microeng 16: 2492-2501.

23] Chen L, Lian G, Han L 2010. Modelling Transdermal Permeation, Part 1. Predicting Skin Permeability of Both Hydrophobic and Hydrophilic Solutes. AICHE 56: 1136-1146

24] Hadgraft J 2004. Skin Deep. Eur. J. Pharm. and Biopharm 58: .291-299.

25] Neelissen JAM, Arth C, Schrijvers AHGJ, Junginger H, Bodde HE 1998. Validation of freeze-drying to visualize percutaneous Hestradiol transport: the influence of skin hydration on the efficacy of the method. Appl Skin Physiol 11: 11-22. 
26] Bodde HE, Van den Brink I, Koerten HK, Dehaan FHN 1991. Visualization of in vitro percutaneous penetration of mercuric chloride transport through intercellular space versus cellular uptake through desmosomes, J. Control. Release 15: 227-236.

27] Michaels AS, Chandrasekaran K, Shaw JE 1975. Drug permeation through human skin: theory and in vitro experimental measurement. Am Inst Chem Engrs J 21: 985-996.

28] Nemanic MK, Elias PM 1980. In situ precipitation: a novel cyotchemical technique for visualization of permeability pathways in mammalian stratum corneum. J Histochem. Cytochem 28: 573-578.

29] Crank J 1964. The mathematics of diffusion. Oxford University Press. London. pp 47-48. ISBN 0198534116

30] Barry BW 1999. Reflections on transdermal drug delivery. Pharm Sci Tech Today 2: 4143.

31] Wang T, Kasting GB, Nitsche JM 2005. A Multiphase Microscopic Diffusion Model for Stratum Corneum Permeability. I. Formulation, Solution, and Illustrative Results for Representative Compounds. J Pharm Sci 95: 620-648.

32] Kalia Y, Guy R 2001. Modeling transdermal drug release. Adv Drug Deliv Rev 48: 159172.

33] Yamashita F, Hashida M 2003. Mechanistic and Empirical Modelling of Skin Permeation of Drugs. Adv Drug Del Rev 55: 1185-1199.

34] Moss GP, Dearden JC, Patel H, Cronin M.T.D (2001). Quantitative structure permeability relationships (QSPRs) for percutaneous absorption. Toxicology in Vitro 16: 299-317

35] Tang H, Mitragotri S, Blankschtein D, Langer R. 2001. Theoretical Description of Transdermal Transport of Hydrophilic Permeants: Application to Low-Frequency Sonophoresis. 90: 545-568. 
36] Tezel A, Sens A, Mitragotri S 2002. Description of Transdermal Transport of Hydrophilic Solutes during Low-Frequency Sonophoresis Based on a Modified Porous Pathway Model. Journal of Pharmaceutical Sciences 92: 381-393

37] Kushner J, Blankschtein D, Langer R 2007. Evaluation of the Porosity, the Tortuosity, and the Hinderance Factor for the Transdermal Delivery of Hydrophilic Permeants in the Context of Aqeous Pore Pathway Hypothesis using Dual-Radiolabeled Permeability Experiments. J Pharm Sci. 96: 3263-3282.

38] Martanto W, Davis SP, Holiday NR, Wang J, Gill HS, Prausnitz MR 2004. Transdermal delivery of Insulin using microneedles in vivo. Pharmaceutical Research, 21: 947-952.

39] Woolfson AD, Morrow DIJ, Morrissey A, Donnelly RF, Mccarron PA 2009. Microneedles/Delivery Device and Method. British Patent Application No 0718996.2. International publication No WO2009040548.

40] Bodde HE, Joosten JGH 1985. A mathematical model for drug release from a two-phase system to a perfect sink. Int J Pharm 26:57-76.

41] Bernardo FP, Saraiva PM 2007. A theoretical Model for Transdermal Drug Delivery from Emulsions and its Dependence Upon Formulation. Journ Pharm Sci 97: 3781-3809.

42] Peck KD, Ghanem AH, Higuchi WI. 1994. Hindered diffusion of polar molecules through and effective pore radii estimates of intact and ethanol treated human epidermal membrane. Pharm. Res 11: 1306- 1314.

43] Deen WM, 1987. Hindered transport of large molecules in liquid-filled pores. AIChE J 33:1409-1425.

44] Lee Y, Hwang K 2002. Skin Thickness of Korean Adults. Surg Radiol Anat 24: 183-189.

45] Kubota K, Dey F, Matar S, Twizell E 2002. A repeated-dose model of percutaneous drug absorption. Appl Math Model 26: 529-544. 
46] Goyal A, Mandapurama S, Michniak B, Simona L 2007. Application of orthogonal collocation and regression techniques for recovering parameters of a two-pathway transdermal drug-delivery model. Computers and Chemical Engineering 31:107-120.

47] Singh S, Singh J 1993. Transdermal drug delivery by passive diffusion and iontophoresis: a review. Medicinal Research Reviews 13: 569-621.

48] Hacker M P, Backmann K, Messer W 2009. Pharmacology: Principles and Practice, Accademic Press, San Diego, California, 201-276.

49] Gupta SK, Southam M, Gale R, Huang SS 1992 System functionality and physicochemical model of Fentanyl transdermal system. J Pain symptom Manage, 7: 517526.

50] Schultz S G, Solomon AK 1981. Determination of the Effective Hydrodynamic Radii of Small Molecules by Viscometry. J Gen Physiol 44: 1189-1199.

51] Bashkatov AN, Genina EA, Sinchkin YP, Kochubey V I, Lakodina NA, Tuchin VV 2003. Glucose and Manitol Diffusion in Human Dura Mater. Biophys J 85:3310-3318.

52] Gefen A, Cornelissen LH, Gawlitta D 2008. The Free Diffusion of Macromolecules in Tissue-Engineered Skeletal Muscle Subjected to Large Compression Strains. J Biomechs 41:845-853.

53] Leddy HA, Haider MA, Guilak F 2006. Diffusional anisotropy in collagenous tissues: fluorescence imaging of continuous point photobleaching. Journal of Biophysics 91:311316.

54] Riches PE, Dhillon N, Lotz J, Woods AW, McNally DS 2002. The internal mechanics of the intervertebral disc under cyclic loading. J Biomechs 35:1263-1271.

55] Al-Qallaf B, Das DB, Davidson A 2009. Transdermal Drug Delivery by Coated Microneedles: Geometry Effects on Drug Concentration in Blood. Asia-Pacific Journal of Chemical Engineering 4, 845-857. 
56] Yan G, Warner KS, Zhang J, Sharma S, Gale BK, 2010. Evaluation needle length and density of microneedle arrays in the pretreatment of skin for transdermal drug delivery. Int J Pharm 391: 7-12.

57] Donnelly, R., Morrow, D.I.J., McCarron, P.A., Woolfson, D.A., Morrissey, A., Juzenas, P., Juzeniene, A., Iani, V., McCarthy, H.O., Moan, J. 2008. Microneedle-mediated intradermal delivery of 5-aminolevulinic acid: Potential for enhanced topical photodynamic therapy. J. Contrl. Rel. 129:154-162.

58] Bal, S.M., Kruithof, A.C., Lieb, H., Tomerius, M., Bouwstra, J., Lademann, J., Meinke, M. (2010). In vivo visualization of microneedle conduits in human skin using laser scanning microscopy. 7:242-246.

59] Martanto, W., Davis, S.P., Holiday, N.R., Wang, J., Gill, H.S., Prausnitz, M.R. (2004) Transdermal delivery of Insulin using microneedles in vivo. Pharmaceutical Research, 21, 947-952. 


\section{List of Figures}

Figure $1 \mathrm{~A}$ schematic showing compressive force exerted by microneedles when inserted into the skin where the grey regions represent areas compressed due to microneedles insertion.

Figure 2 Effect of strain level on diffusion coefficient. The graph compares experimental data [14] showing changes in diffusion coefficient of glucose when different strains are applied to annulus fibrosus, with simulation results based on the proposed model, of different microneedle geometry exerting similar strain on the skin. Strain is calculated using equation (17) and the comparison is done to validate the modelling results.

Figure 3 Effect of the length of microneedles on diffusive flux of Fentanyl

Figure 4 Effect of tip radius of microneedles on diffusive flux of Fentanyl

Figure 5 Effect of base radius of microneedles on diffusive flux of Fentanyl

Figure 6 Effect of the number of microneedles on diffusive flux of Fentanyl

Figure 7 Effect of base radius of microneedles on peak blood concentration of Fentanyl. 
Figure 8 Effect of tip radius on peak blood concentration of Fentanyl

Figure 9 Effect of length of microneedles on peak blood concentration of Fentanyl

Figure 10 Effect of Number of microneedles on Peak blood concentration of Fentanyl. 


\section{List of Tables}

Table 1 Values of parameters used in this study except where stated otherwise. Values used are similar to those of Fentanyl. 
Table 1 Values of parameters used in this study except where stated otherwise. Values used are similar to those of Fentanyl.

\begin{tabular}{|c|c|}
\hline Parameter & Value \\
\hline Porosity of VE, $\varepsilon$ & 0.00002 (Kushner et al, 2007) \\
\hline Tortuosity, $\tau$ & 2.5 (Kushner et al, 2007) \\
\hline Thickness of VE, h (m) & 0.00018 (Hwang et al, 2002) \\
\hline Radius of VE pore, $\mathrm{r}_{\mathrm{s}}(\mathrm{m})$ & 0.00000088 (Kushner et al, 2007) \\
\hline Hydrodynamic radius, $\mathrm{r}_{\mathrm{p}}(\mathrm{m})$ & 0.00000026 (Tezel et al, 2002) \\
\hline Diffusion coefficient at infinite dilution, D ( $\left.\mathrm{m}^{2} / \mathrm{s}\right)$ & $9.75 \times 10^{-6}$ (Peck et al, 1996) \\
\hline Volume of distribution, $\mathrm{V}_{\mathrm{b}}(\mathrm{ml})$ & 731000 (Tojo, 2005) \\
\hline Elimination rate constant, $\mathrm{k}_{\mathrm{e}}\left(\mathrm{s}^{-1}\right)$ & 0.0000284 (Tojo, 2005) \\
\hline $\begin{array}{l}\text { Concentration of drug on skin surface, } C_{s} \\
(\mu \mathrm{g} / \mathrm{ml})\end{array}$ & 15800 (Тojo, 2005) \\
\hline
\end{tabular}




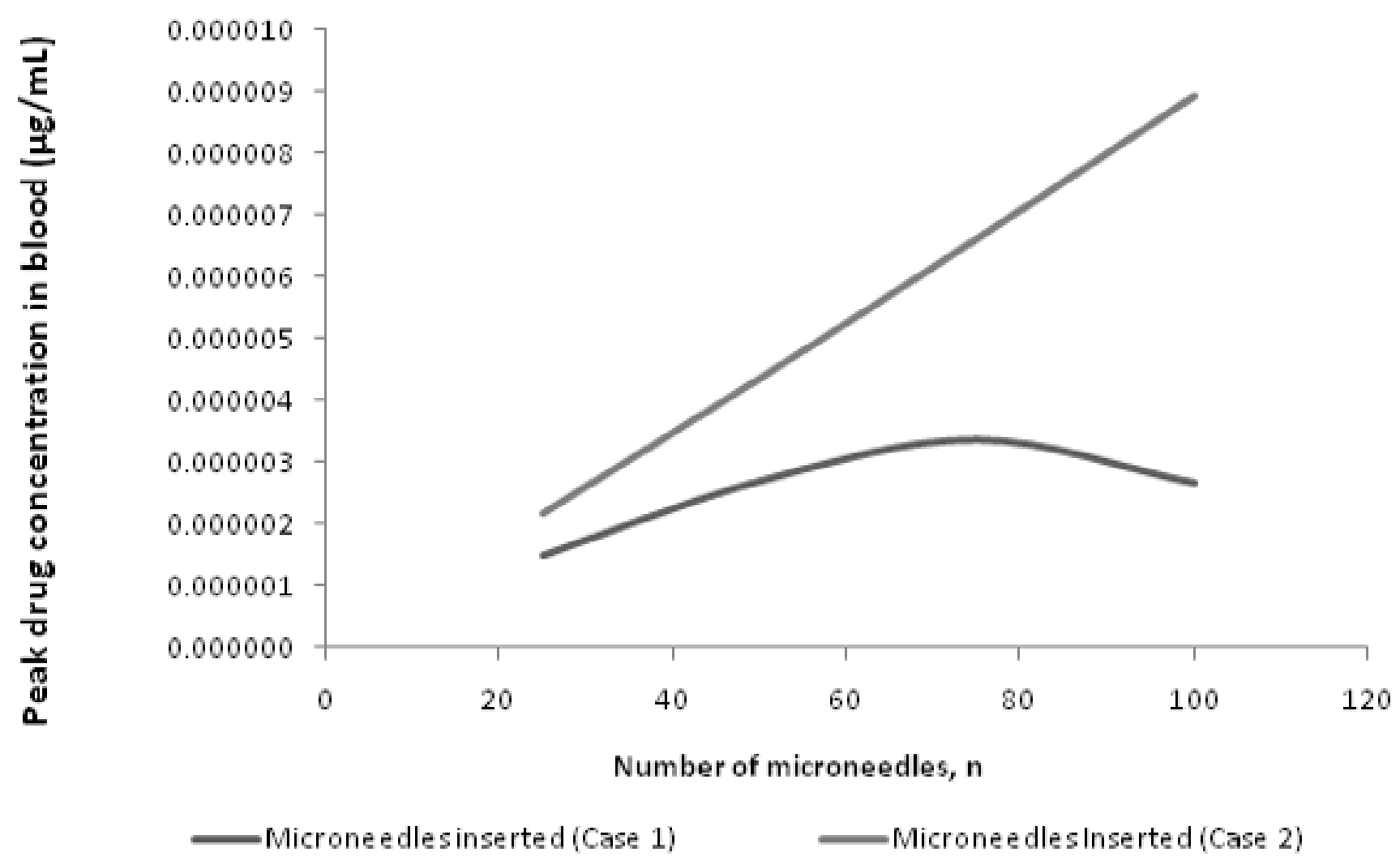

Figure 10 Effect of Number of microneedles on Peak blood concentration of Fentanyl. 
Microneedles on skin surface prior to

insertion

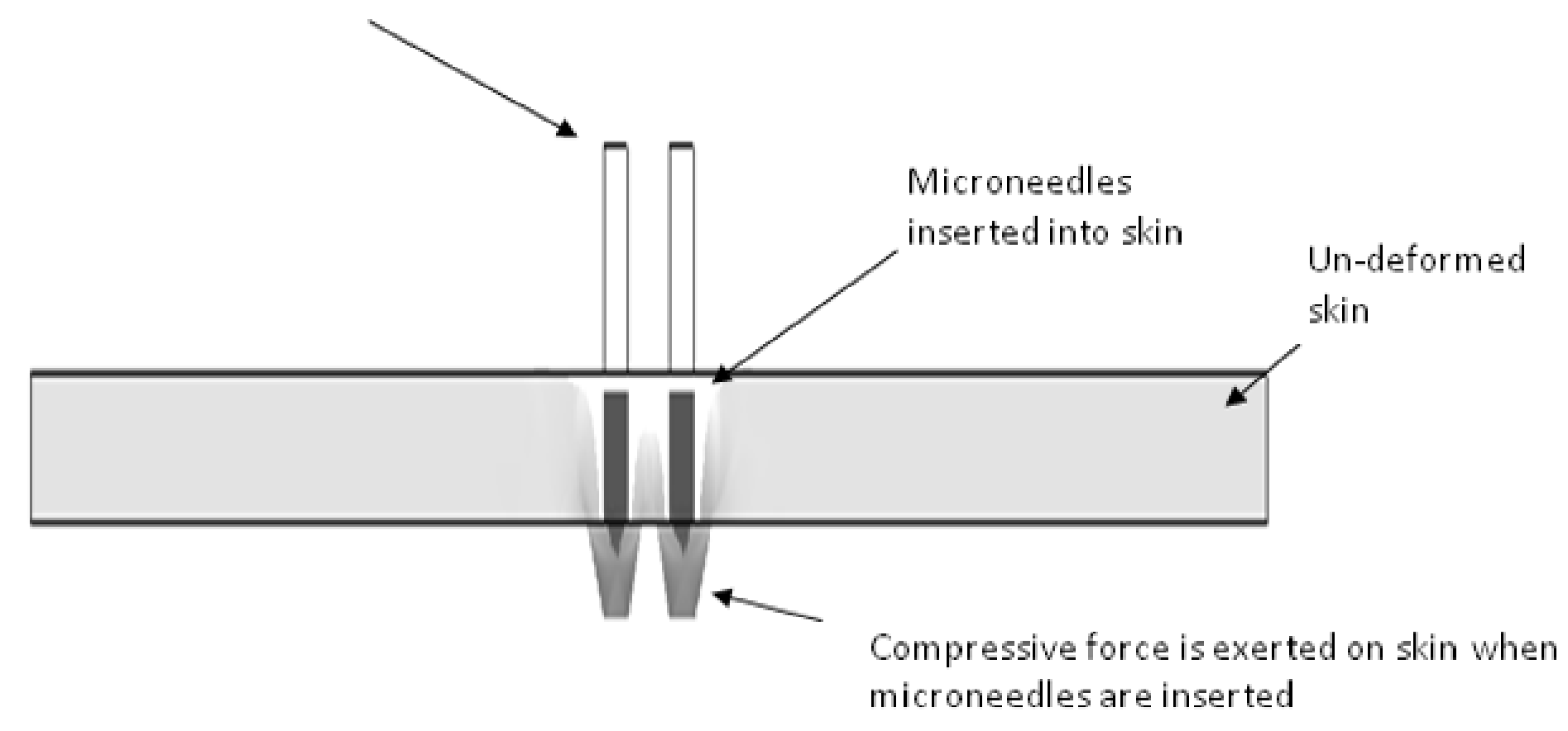

Figure $1 \mathrm{~A}$ schematic showing compressive force exerted by microneedles when inserted into the skin where the grey regions represent areas compressed due to microneedles insertion. 


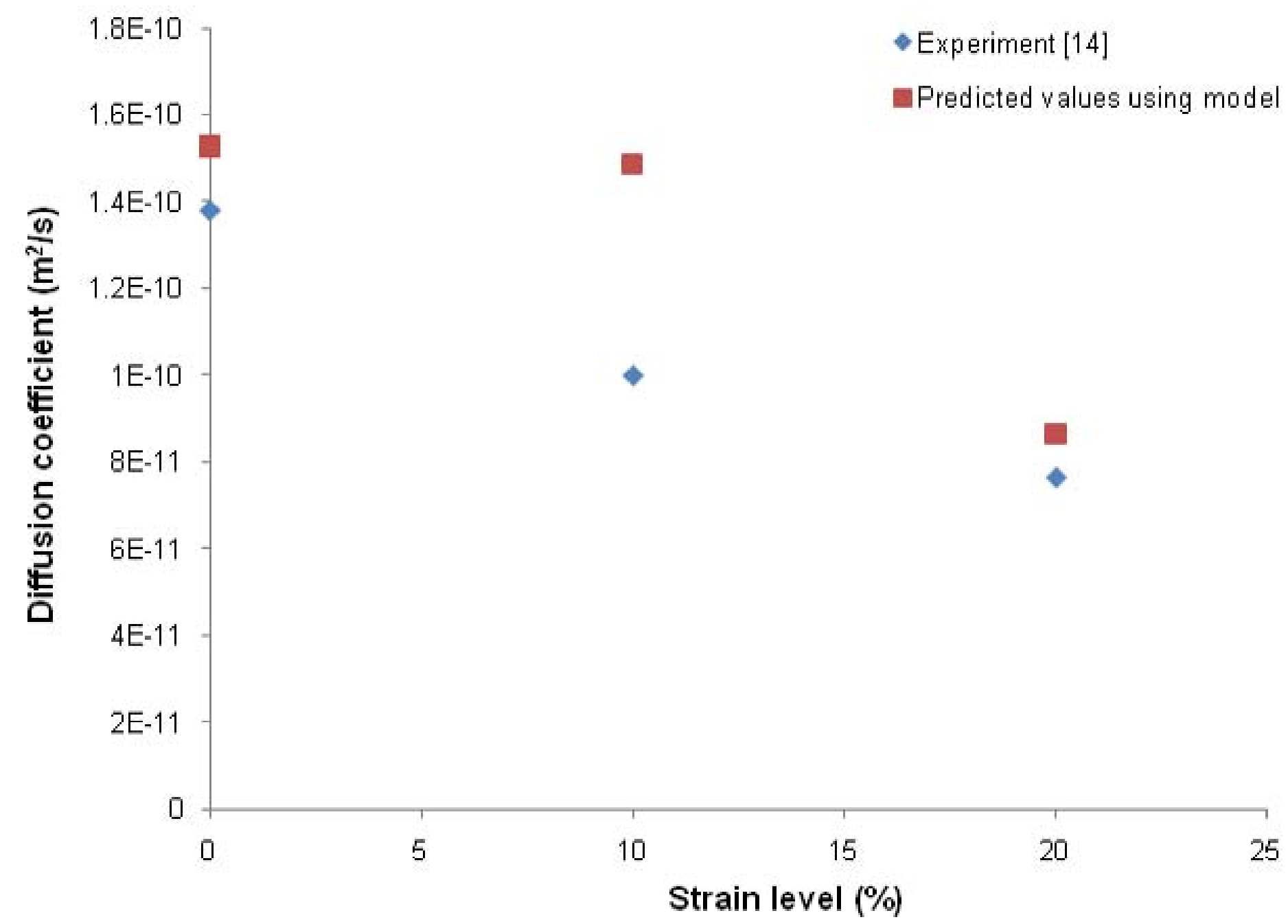

Figure 2 Effect of strain level on diffusion coefficient. The graph compares experimental data [14] showing changes in diffusion coefficient of glucose when different strains are applied to annulus fibrosus, with simulation results based on the proposed model, of different microneedle geometry exerting similar strain on the skin. Strain is calculated using equation (17) and the comparison is done to validate the modelling results. 


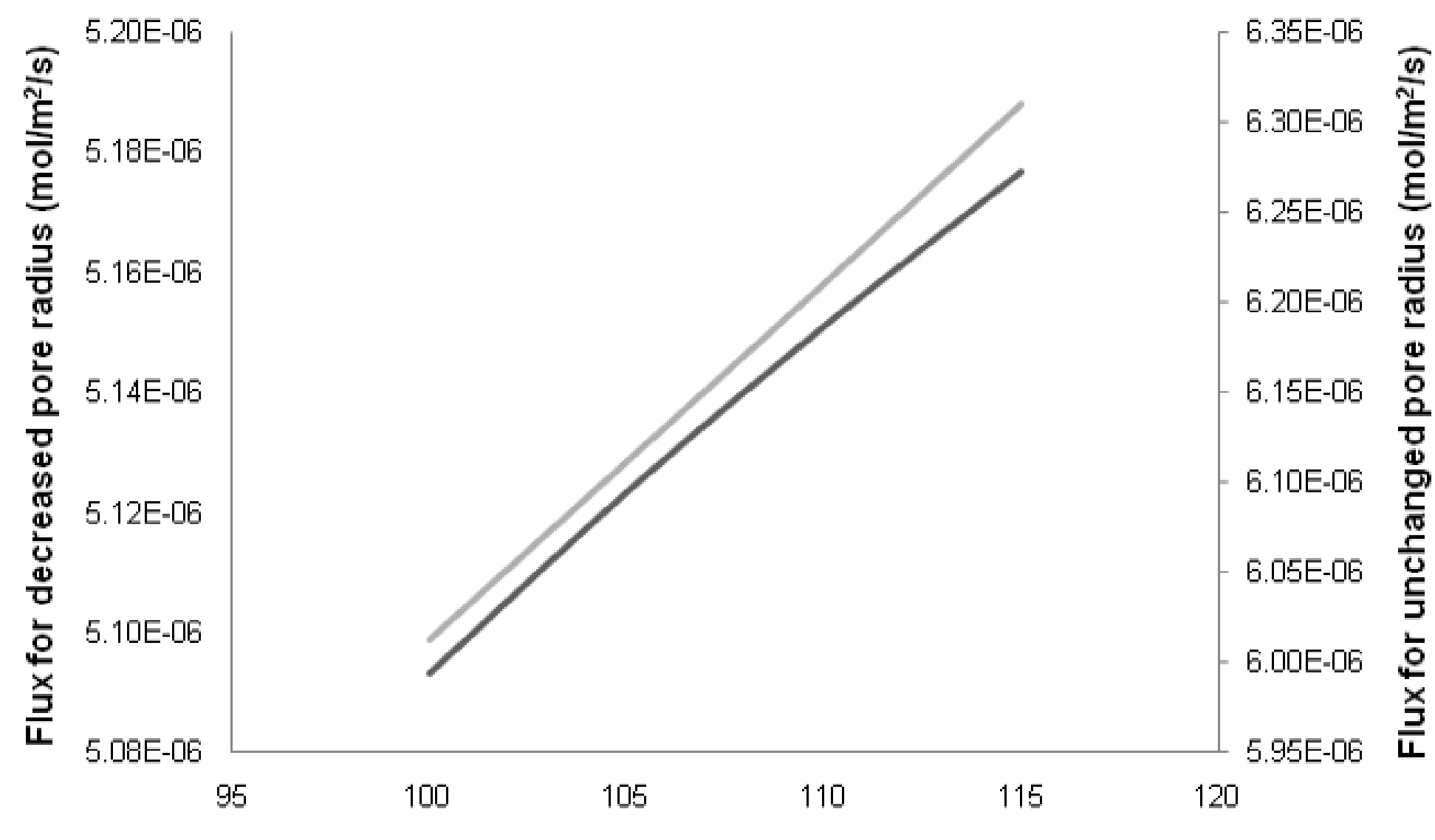

Penetrated Length L ( $\mu \mathrm{m})$

-Decreased pore radius

Unchanged pore radius

Figure 3 Effect of the length of microneedles on diffusive flux of Fentanyl 


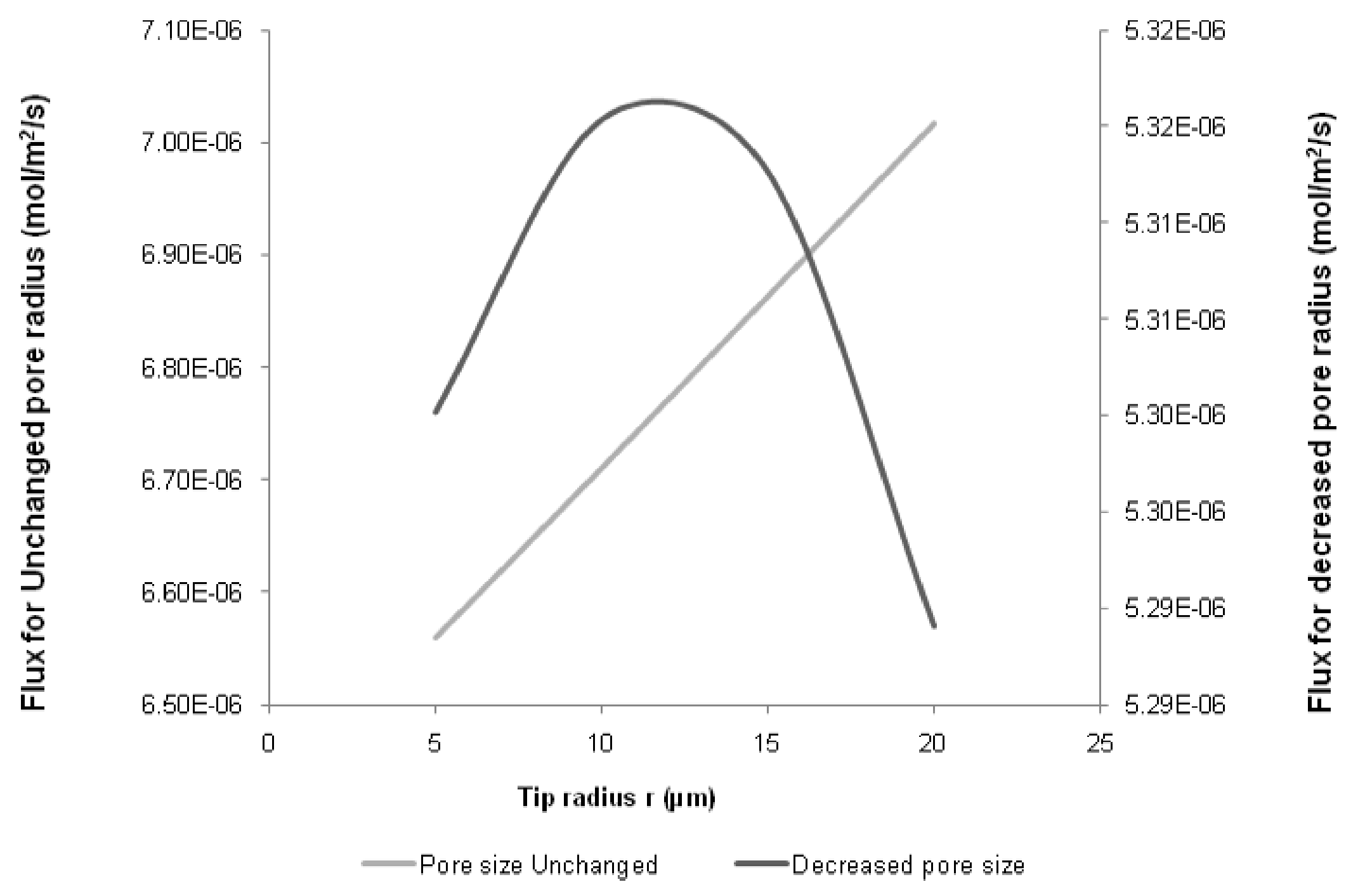

Figure 4 Effect of tip radius of microneedles on diffusive flux of Fentanyl 


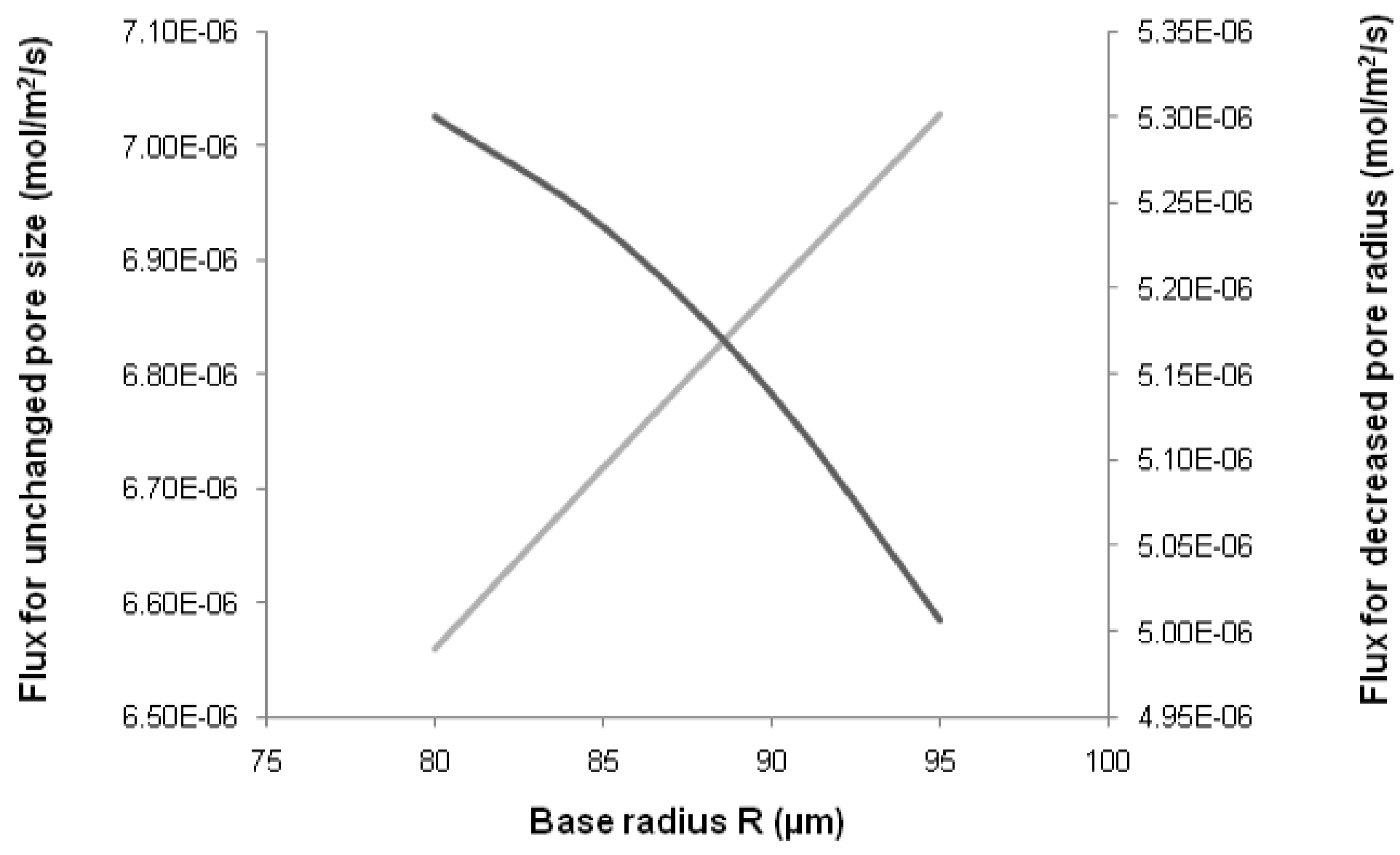

Unchanged pore radius

Decreased pore radius

Figure 5 Effect of base radius of microneedles on diffusive flux of Fentanyl 


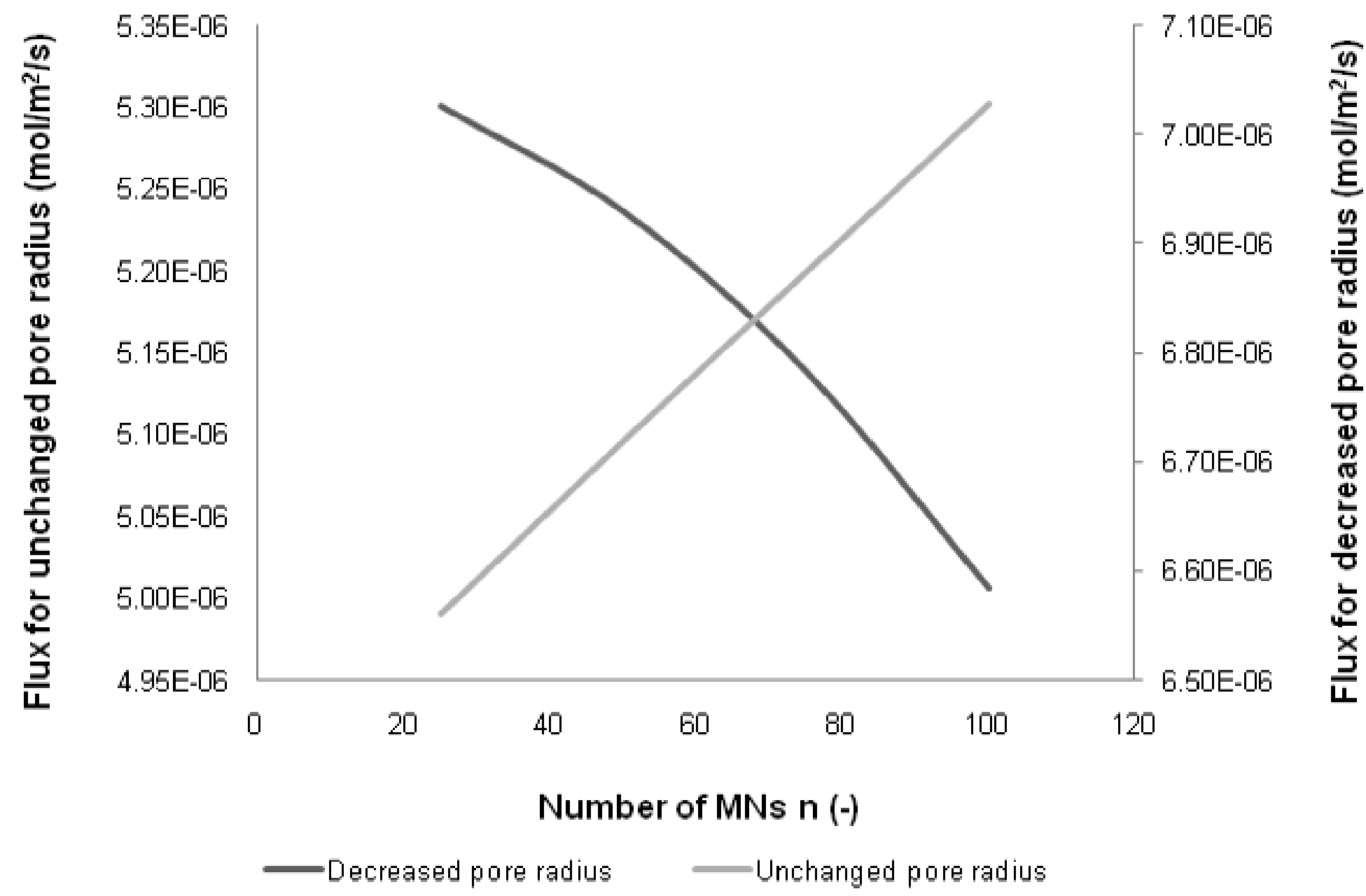

Figure 6 Effect of the number of microneedles on diffusive flux of Fentanyl 


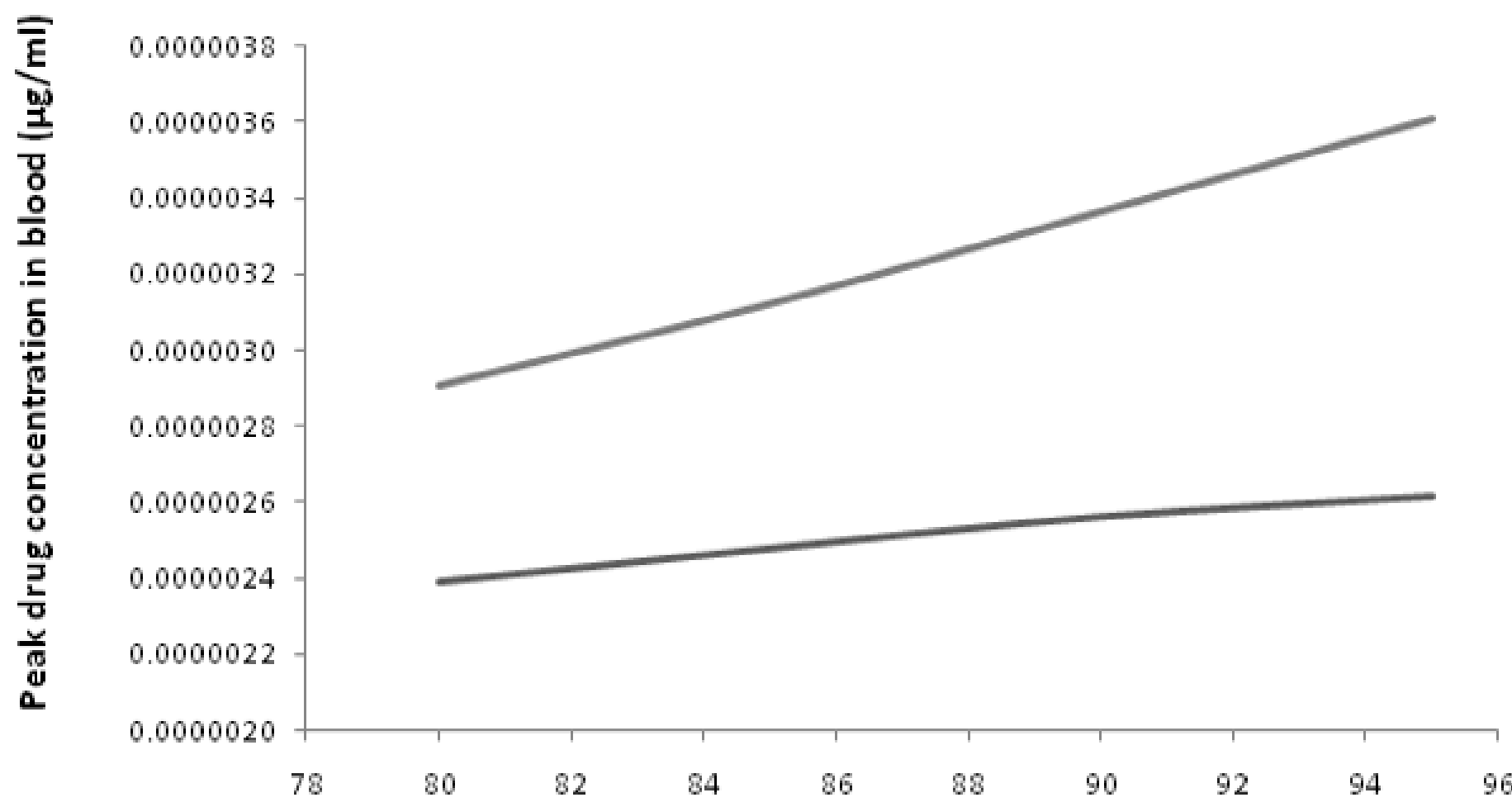

Base radius of microneedle, $\mathrm{R}(\mu \mathrm{m})$

-Microneedlesinserted (Case 1) Microneedlesinserted (Case 2)

Figure 7 Effect of base radius of microneedles on peak blood concentration of Fentanyl. 


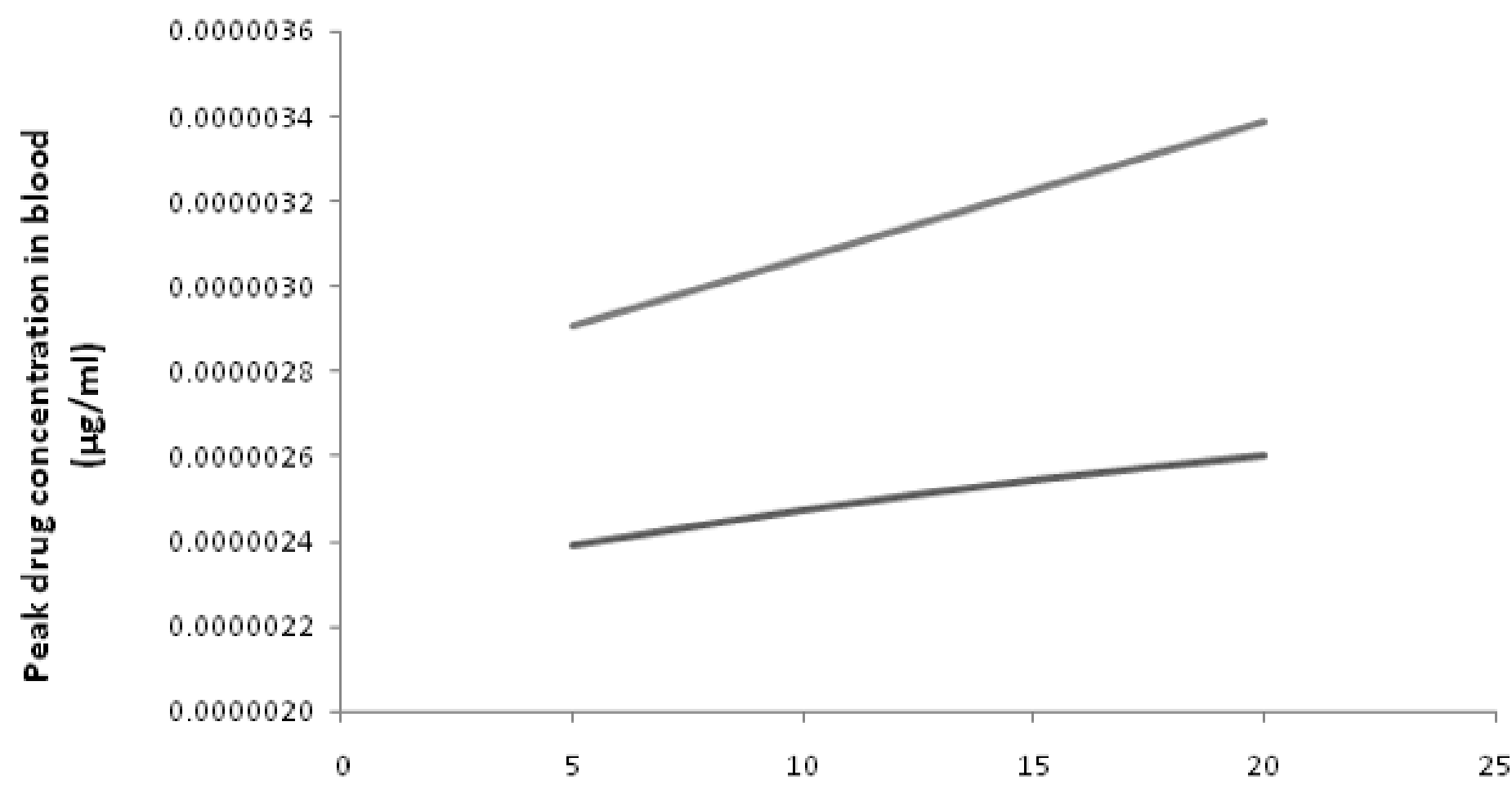

Tip radius of microneedle, $r(\mu \mathrm{m})$

Microne e dle inserted (Case 1)

Microne edle sinserted (Case 2)

Figure 8 Effect of tip radius on peak blood concentration of Fentanyl 


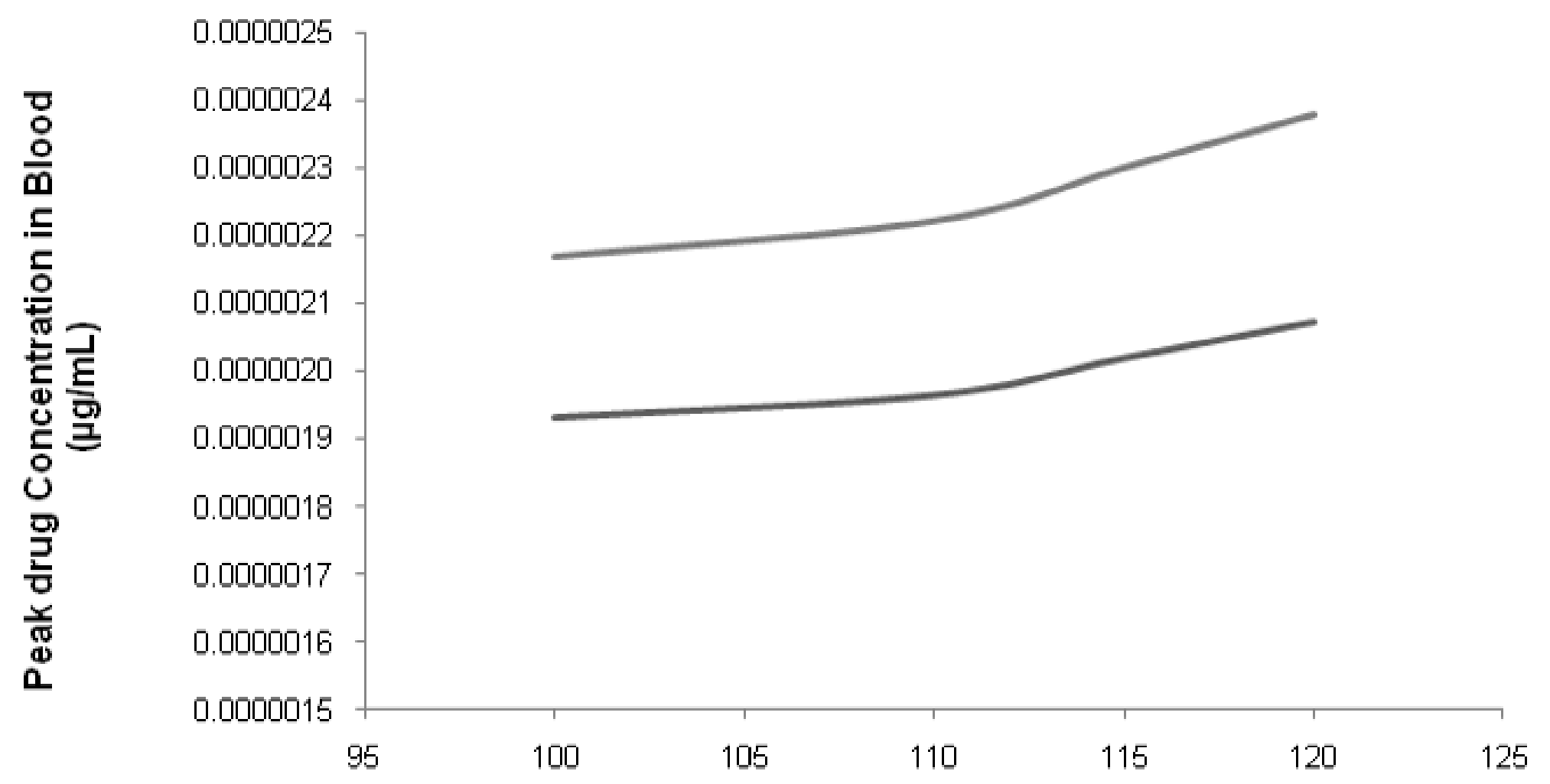

Length of microneedle, $L(\mu \mathrm{m})$

-Microneedles inserted (Case 1) - Microneedles inserted (Case 2)

Figure 9 Effect of length of microneedles on peak blood concentration of Fentanyl 